\title{
Use of the Derriford Appearance Scale 59 to assess patient-reported outcomes in secondary cleft surgery
}

\author{
Sophie Ricketts MBBS, Eran Regev MD, Oleh M Antonyshyn MD, Alex Kiss PhD, Jeffrey A Fialkov MD
}

S Ricketts, E Regev, OM Antonyshyn, A Kiss, JA Fialkov. Use of the Derriford Appearance Scale 59 to assess patient-reported outcomes in secondary cleft surgery. Plast Surg 2016;24(1):27-31.

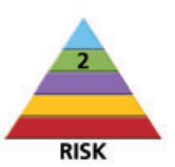

BACKGROUND: Secondary rhinoplasty, one of the final procedures in addressing the stigma of the cleft lip and palate (CLP), has both functional and aesthetic objectives. The way in which physicians evaluate outcomes in surgery concerning aesthetics is changing. Well-designed patient-reported outcome measures to assess health-related quality of life improvements attributable to surgery are increasingly being used. The Derriford Appearance Scale 59 (DAS-59) is currently the only available validated patient-reported outcome measure that assesses concern about physical appearance.

METHODS: Twenty patients with CLP presenting between May 2009 and May 2013 for secondary rhinoplasty to Sunnybrook Health Sciences Centre (Toronto, Ontario) were recruited. DAS-59 measures were administered both preoperatively and at least six months after surgery. Pre- and postoperative measures were scored and compared. Item-by-item analysis of the measure was also performed.

RESULTS: Total scores for this CLP group indicated greater concern about appearance than the general population. Across all subscales of the measure, there was a reduction in scores after secondary rhinoplasty suggesting less patient concern with appearance and a positive effect of surgery on patient quality of life. Item-by-item analysis suggested relatively few items in the measure were driving overall change in total scores.

CONCLUSION: Comparison of pre- and postoperative scores with the DAS-59 in secondary cleft rhinoplasty suggests there is less concern with appearance after surgery. However, a small number of items within this generic scale contributing to this difference may suggest the need for a more patient specific measure for assessment of surgical outcomes in the cleft population.

Key Words: Cleft lip and palate; Cleft rhinoplasty; DAS-59; Derriford Appearance Scale; Patient-reported outcomes

\author{
L'utilisation de l'échelle d'apparence Derriford en \\ 59 éléments pour évaluer les résultats d'une \\ chirurgie secondaire de la fente labio-palatine de \\ l'avis des patients
}

HISTORIQUE : La rhinoplastie secondaire, l'une des dernières interventions pour corriger une fente labio-palatine (FLP), a des objectifs à la fois fonctionnels et esthétiques. La manière dont les médecins évaluent les résultats esthétiques après une chirurgie est en évolution. Ils utilisent de plus en plus des mesures de résultats bien conçues faites par les patients pour évaluer les améliorations à la qualité de vie liée à la santé découlant de l'opération. Léchelle d'apparence Derriford en 59 éléments (DAS-59) est la seule mesure validée de résultats déclarés par le patient pour évaluer les préoccupations relatives à l'apparence physique.

MÉTHODOLOGIE : Les chercheurs ont recruté 20 patients ayant une FLP qui ont consulté au Sunnybrook Health Sciences Centre de Toronto, en Ontario, entre mai 2009 et mai 2013 pour subir une rhinoplastie secondaire. Ils ont administré les mesures de DAS-59 avant et au moins six mois après l'opération. Ils ont établi les scores des mesures préopératoires et postopératoires et les ont comparées. Ils ont également analysé chaque élément de la mesure.

RÉSULTATS : Le score total de ce groupe de FLP s'associait à une plus grande préoccupation relative à l'apparence qu'au sein de la population générale. Dans toutes les sous-échelles de la mesure, les scores diminuaient après la rhinoplastie secondaire, ce qui laisse supposer que les patients se préoccupaient moins de leur apparence et que l'opération avait eu un effet positif sur leur qualité de vie. L'analyse de chaque élément indiquait que relativement peu d'éléments de la mesure suscitaient le changement des scores totaux.

CONCLUSION : La comparaison des scores de la DAS-59 avant et après une rhinoplastie secondaire de la FLP indique une moindre préoccupation de l'apparence après l'opération. Cependant, peu d'éléments de cette échelle générique contribuent à cette différence, ce qui laisse croire à la nécessité d'utiliser une mesure plus précise pour évaluer les résultats chirurgicaux au sein de cette population.

\footnotetext{
Drimary cleft lip repair often incorporates correction of the cleft nose 1 to reduce the psychosocial consequences of an uncorrected facial difference; however, it does not always eliminate the need for future secondary surgery (1). It is this aspect of cleft lip and/or palate (CLP) facial difference that is most likely to require secondary surgery in early adulthood. The purpose of this surgery is to achieve a more 'normal' nasal appearance by addressing the asymmetry and the stigma associated with CLP. Goals of this surgery are sometimes functional (airway) but are also significantly aesthetic. It alters the individual's facial appearance, and this changes the way in which they perceive themselves, the way they are perceived by others and, therefore, impacts psychological and social well-being $(2,3)$. The method of evaluation of the outcomes of this surgery, with significant aesthetic goals, deserves consideration.

Assessment of treatment interventions or surgery has conventionally been performed by physicians. This outcome assessment may include photographic analysis, anatomical measurements and complications. These measures, although important, do not capture the patient's satisfaction - their perception of the result or their healthrelated quality of life ( $\mathrm{QoL})$. The patient perspective is particularly relevant in facial reconstructive surgery where the impact on patients' QoL is complex and not necessarily reflected in objective physicianinterpreted outcomes $(4,5)$.

Assessing the perspective of a patient with CLP in relation to function, aesthetics and psychosocial well-being should be paramount in measuring surgical outcomes. Patient-reported outcomes (PROs) are concepts that are important to patients with different health conditions. PROs can be measured using purposely designed questionnaires that measure the patient's perspective without interpretation from anyone else. Such measures can capture concepts, such as health-related QoL (a multidomain concept with physical, psychological and social components), and can be used to provide evidence of a treatment benefit from the patient's perspective (6).

Many PRO instruments have been used in plastic surgery; however, for a PRO instrument to be scientifically sound it should assess the impact of surgical intervention in a clinically meaningful manner (7). The majority of measures in plastic surgery have not been formally developed in a standardized manner (ie, they have not been tested for reliability [ability to produce consistent scores], validity [ability to measure what is intended to be measured] or responsiveness [ability to measure change]). Reviews of the literature have revealed the lack of a cleft-specific PRO instrument to assess QoL in CLP patients $(8,9)$. In clinical practice, given the lack of a PRO instrument for patients with CLP, generic instruments, or non-disease-specific tools such as the Pediatric Quality of Life Inventory and Child Health Questionnaire have been used as a substitute $(10,11)$.
} 
TABLE 1

Normative Derriford Appearance Scale 59 data for the general population in those 'not concerned' and 'concerned' with their appearance* as well as the study population preoperatively

\begin{tabular}{lccccc}
\hline & \multicolumn{4}{c}{ General population } & \multirow{2}{c}{$\begin{array}{c}\text { Cleft } \\
\text { population }\end{array}$} \\
\cline { 2 - 5 } & \multicolumn{2}{c}{ Not concerned } & \multicolumn{2}{c}{ Concerned } & $19-47$ \\
Age, years & $18-30$ & $31-60$ & $18-30$ & $31-60$ & $19-60$ \\
Men & $\mathrm{n}=50$ & $\mathrm{n}=156$ & $\mathrm{n}=60$ & $\mathrm{n}=80$ & $\mathrm{n}=9$ \\
Score $^{\dagger}$ & $33.3 \pm 18.5$ & $32.0 \pm 22$ & $85.5 \pm 34.2$ & $76.7 \pm 33.3$ & $92 \pm 28.1$ \\
Women & $\mathrm{n}=57$ & $\mathrm{n}=123$ & $\mathrm{n}=102$ & $\mathrm{n}=188$ & $\mathrm{n}=11$ \\
Score $^{\dagger}$ & $40 \pm 26.2$ & $22 \pm 16.9$ & $86.1 \pm 37.1$ & $82.2 \pm 39.2$ & $112 \pm 39.7$ \\
\hline
\end{tabular}

*Adapted from reference $13 ;{ }^{\dagger}$ Data presented as mean $\pm S D$

The Derriford Appearance Scale (DAS) is QoL measure developed for assessing concern about physical appearance. This is a standardized, psychometrically sound, factorial scale (displayed high internal consistency [0.98] and acceptable test-retest reliabilities [0.75 to 0.86]). The original DAS uses 59 items and is suited for detailed clinical investigation or assessment of the individual $(12,13)$. The DAS was identified by Ching et al (14) in a comprehensive literature review as an ideal candidate for future study because of its specific development for use in aesthetic surgery.

The DAS measures the underlying construct of adjustment to problems in appearance. It comprises an introductory section in which subjects identify and describe aspects of appearance of which they are most self-conscious, referred to as their 'feature', in scale items. Participant responses relate to concerns and behaviours within the context of overall self-consciousness (15).

To standardize the DAS-59, authors placed the scores of the clinical population in context with scores of others in comparable populations (consisting of the general population who are concerned, and who are not concerned, about appearance). Because the DAS-59 discriminates differences in levels of distress and dysfunction between men and women and between different times of life, normative data for each sex were tabulated in their study for early adulthood (18 to 30 years of age), mid-adulthood (31 to 60 years of age) and late adulthood ( $\geq 60$ years of age). These normative data enabled a comparison with the study population (Table 1 ).

It has been shown that CLP has a negative impact on the patient's QoL (16-18). The difficulties relate to dissatisfaction with facial appearance, lower levels of self-esteem, and experiences of discrimination in employment and social settings (19). Despite the prevalence of nasal deformity among the stigma of CLP, no study has used a validated tool to quantify the effect of secondary rhinoplasty on the QoL of CLP patients. The overall goal of the present study was to explore appearance-related concerns using the DAS-59 in a sample of adultaged patients with CLP undergoing a secondary rhinoplasty. The specific aims were twofold: to compare appearance-related concerns in the sample of secondary rhinoplasty patients with normative data; and to measure change in appearance related $\mathrm{QoL}$ following surgery.

\section{METHODS}

Patients undergoing secondary cleft rhinoplasty at the authors' institution by one of two surgeons were identified prospectively between May 2009 and May 2013. The study was approved by the hospital research ethics board. Patients willing to participate completed the DAS-59 questionnaire before their surgery and then subsequently 11 months postsurgery (range six to 42 months). The DAS contains 59 items that measure six concepts: general self-consciousness of appearance (GSC); social self-consciousness of appearance (SSC); sexual and bodily self-consciousness of appearance (SBSC); negative self-concept (NSC); facial self-consciousness of appearance (FSC) and physical distress and dysfunction (Phys). In addition, a total score (full scale [FS]) can be obtained by summing items. Completed questionnaires were scored according to the DAS manual. The first
TABLE 2

Comparisons of Derriford Appearance Scale 59 (DAS-59) scores of appearance pre- and postsecondary cleft rhinoplasty surgery according to subscale

\begin{tabular}{lcccc}
\hline $\begin{array}{l}\text { DAS-59 } \\
\text { subscale }\end{array}$ & Preoperative & Postoperative & $\begin{array}{c}\text { Mean } \\
\text { difference }\end{array}$ & $\mathbf{P}$ \\
\hline FS & $96.95 \pm 38.34$ & $79.50 \pm 29.94$ & 17.45 & 0.0024 \\
GSC & $39.90 \pm 17.04$ & $30.25 \pm 14.49$ & 9.65 & 0.0006 \\
SSC & $27.85 \pm 13.46$ & $22.95 \pm 8.75$ & 4.90 & 0.0288 \\
SBSC & $10.30 \pm 5.17$ & $8.05 \pm 3.58$ & 2.25 & 0.0280 \\
NSC & $14.00 \pm 5.17$ & $11.20 \pm 3.59$ & 2.80 & 0.0011 \\
FSC & $4.05 \pm 2.78$ & $3.20 \pm 1.94$ & 0.85 & 0.1899 \\
Phys & $2.85 \pm 1.57$ & $2.45 \pm 1.39$ & 0.40 & 0.3722 \\
\hline
\end{tabular}

Data presented as mean \pm SD unless otherwise indicated. *t test. FSC Facial self-consciousness; FS Full scale; GSC General self-consciousness; NSC Negative self-concept; Phys Physical distress and dysfunction; SBSC Sexual and bodily self-consciousness; SSC Social self-consciousness

set of items measure frequency of avoidance behaviours on a fourpoint Likert scale from "almost never" to "almost always". The second set of items assesses emotional distress relating to their feature and the final set of items measure aspects of self-concept relevant to living with an appearance problem, both of which are measured on a five-point Likert scale from "not at all distressed" to "extremely distressed". For each subscale, lower scores indicate less concern or less self-consciousness regarding their 'feature'. Throughout the scale, 'no answer' scores 0 and items 52, 54, 55, 56 and 57 have their scores reversed. Potential range of the FS is 0 to 249. In addition to the DAS, demographic data (age, sex, occupation, family status, nationality and ethnicity) were gathered as well as type of cleft (unilateral, bilateral, cleft lip and or palate alone).

\section{Analysis}

Descriptive statistics, including mean $( \pm S D)$, were calculated for both the scale/subscales and individual items. Preoperative scores for the sample were compared with normative data. In addition, paired $t$ tests and Wilcoxon signed-rank tests were computed for the total score, subscales and each item to examine change following surgery. To identify DAS-59 content most relevant to measuring change following surgery, paired $t$ tests and Wilcoxon signed-rank tests were computed for each item. Participants with missing values in postoperative scores were excluded from the analysis. All analyses were performed using SAS version 9.3 (SAS Institute, USA).

\section{RESULTS}

Twenty consecutive patients presented for secondary cleft rhinoplasty surgery between May 2009 and May 2013. Patients' mean age at surgery was 30 years (range 19 to 47 years; 11 male, nine female). Four patients had bilateral and 16 had unilateral CLP.

Table 1 shows the sample scores compared with population norms. Cleft patients from the study population had generally higher DAS scores (male mean $=92$; female mean $=112$ ) than the general population data $($ male mean $=29.3$ to 85.5 ; female mean $=22.0$ to 115.3 ; range being dependent on age and classification of whether concerned or not concerned with appearance) (13).

Table 2 shows the scores for the sample before and after surgery and $\mathrm{P}$ value for difference in scores. Specifically, patients reported significantly better scores in terms of the FS, GSC, SSC, SBSC and NSC scores $(\mathrm{P}<0.05)$. Neither the decreases in facial self-consciousness (FSC) nor Phys were statistically significant in this group.

Because the DAS-59 is a generic tool that was designed with all types of cosmetic surgery patients in mind and, therefore, not developed specifically for the cleft population, change at the item level was examined to identify content that is relevant to the cleft population. Table 3 shows the mean values pre- and postoperatively at 
TABLE 3

Item analysis. Mean difference in pre- versus postoperative item scores*

\begin{tabular}{|c|c|c|c|c|c|c|}
\hline & Items & Label & Preoperative & Postoperative & Mean difference & $\mathbf{P}^{\dagger}$ \\
\hline \multirow[t]{10}{*}{ GSC } & Item1 & Self-consciousness of 'feature' & $2.84 \pm 1.07$ & $1.89 \pm 1.29$ & 0.95 & 0.0135 \\
\hline & Item10 & Avoiding photography & $2.26 \pm 1.15$ & $1.53 \pm 0.9$ & 0.74 & 0.0017 \\
\hline & Item15 & Raising subject of the 'feature' in conversation before others do & $1.42 \pm 0.69$ & $1.32 \pm 0.75$ & 0.11 & 0.5778 \\
\hline & Item17 & Being irritable at home & $1.58 \pm 0.84$ & $1.42 \pm 0.61$ & 0.16 & 0.2680 \\
\hline & Item27 & Feel unattractive & $2.68 \pm 1.11$ & $2.05 \pm 0.97$ & 0.63 & 0.0020 \\
\hline & Item31 & Feel inferior & $1.84 \pm 1.17$ & $1.47 \pm 0.96$ & 0.37 & 0.1298 \\
\hline & Item34 & Distress when others make remarks & $3 \pm 1.56$ & $2.05 \pm 1.58$ & 0.95 & 0.0376 \\
\hline & Item35 & Distress when others stare & $2.68 \pm 1.67$ & $1.95 \pm 1.61$ & 0.74 & 0.0742 \\
\hline & Item36 & Distress when others ask about the 'feature' & $2.26 \pm 1.52$ & $1.68 \pm 1.34$ & 0.58 & 0.1421 \\
\hline & Item38 & Distress when seen in a particular view & $2.79 \pm 1.72$ & $2 \pm 1.49$ & 0.79 & 0.0605 \\
\hline \multirow{11}{*}{ ssc } & Item3 & Difficulty making friends & $1.32 \pm 0.89$ & $1.26 \pm 0.65$ & 0.05 & 0.8256 \\
\hline & Item5 & Avoiding school/college/work & $0.95 \pm 0.52$ & $0.95 \pm 0.52$ & 0 & 1.0000 \\
\hline & Item6 & Avoiding pubs/restaurants & $1.16 \pm 0.69$ & $1.05 \pm 0.4$ & 0.11 & 0.5778 \\
\hline & Item7 & Avoiding parties/discos & $1.42 \pm 1.07$ & $1.16 \pm 0.83$ & 0.26 & 0.2871 \\
\hline & Item13 & Avoiding department stores & $1.58 \pm 2.36$ & $1 \pm 0.47$ & 0.58 & 0.2999 \\
\hline & Item14 & Avoid leaving the house & $1.21 \pm 0.63$ & $1.53 \pm 2.37$ & -0.32 & 0.5742 \\
\hline & Item16 & Closing into a shell & $1.58 \pm 0.84$ & $1.32 \pm 0.75$ & 0.26 & 0.1716 \\
\hline & Item18 & Being misjudged & $1.63 \pm 0.76$ & $1.26 \pm 0.81$ & 0.37 & 0.1100 \\
\hline & Item19 & Previous avoidance of school/college/work & $1.53 \pm 1.07$ & $1.53 \pm 0.84$ & 0 & 1.0000 \\
\hline & Item20 & Feeling an embarrassment to friends & $1.32 \pm 0.67$ & $1.21 \pm 0.85$ & 0.11 & 0.6065 \\
\hline & Item21 & Feeling a freak & $1.53 \pm 1.12$ & $1.21 \pm 0.71$ & 0.32 & 0.1374 \\
\hline \multirow[t]{9}{*}{ SBSC } & Item4 & Avoiding undressing in front of partner & $0.84 \pm 1.21$ & $1 \pm 1.05$ & -0.16 & 0.2860 \\
\hline & Item9 & Avoiding communal changing rooms & $1.37 \pm 0.96$ & $1.05 \pm 0.78$ & 0.32 & 0.2680 \\
\hline & Item23 & Adverse effect on sex life & $1.47 \pm 1.17$ & $1.32 \pm 1.16$ & 0.16 & 0.4202 \\
\hline & Item24 & Adverse effect on marriage & $0.58 \pm 0.61$ & $0.53 \pm 0.61$ & 0.05 & 0.5778 \\
\hline & Item37 & Distress when going to beach & $1.7 \pm 1.4$ & $1.21 \pm 0.92$ & 0.58 & 0.1343 \\
\hline & Item43 & Distress from being unable to wear favorite clothes & $0.89 \pm 1.15$ & $0.74 \pm 1.15$ & 0.16 & 0.4535 \\
\hline & Item45 & Distress from being unable to go swimming & $0.58 \pm 0.51$ & $0.53 \pm 0.61$ & 0.05 & 0.8041 \\
\hline & Item46 & Distress from being unable to play games & $0.58 \pm 0.51$ & $0.42 \pm 0.51$ & 0.16 & 0.3800 \\
\hline & Item49 & Distress from being unable to look in mirror & $1.79 \pm 1.58$ & $1.11 \pm 1.29$ & 0.68 & 0.0439 \\
\hline \multirow[t]{5}{*}{ NSC } & Item52 & How confident do you feel? & $2.95 \pm 1.22$ & $2.37 \pm 0.83$ & 0.58 & 0.0119 \\
\hline & Item54 & How secure do you feel? & $3.11 \pm 1.24$ & $2.26 \pm 0.93$ & 0.84 & 0.0007 \\
\hline & Item55 & How cheerful do you feel? & $2.58 \pm 1.39$ & $2 \pm 0.88$ & 0.58 & 0.0526 \\
\hline & Item56 & How normal do you feel? & $2.68 \pm 1.2$ & $2.26 \pm 0.73$ & 0.42 & 0.1036 \\
\hline & Item57 & How masculine/feminine do you feel? & $2.47 \pm 1.22$ & $2.42 \pm 1.17$ & 0.05 & 0.7899 \\
\hline \multirow[t]{4}{*}{$\mathrm{FSC}$} & Item11 & Avoid getting the hair & $1.42 \pm 1.35$ & $1.05 \pm 0.91$ & 0.37 & 0.2175 \\
\hline & Item44 & Distress from being unable to change hairstyle & $1.05 \pm 1.31$ & $0.63 \pm 0.76$ & 0.42 & 0.1628 \\
\hline & Item48 & Distress from being unable to answer the front door & $0.84 \pm 0.76$ & $0.84 \pm 1.01$ & 0 & 1.0000 \\
\hline & Item51 & Distress from being unable to go out in windy weather & $0.63 \pm 0.5$ & $0.74 \pm 1.15$ & -0.11 & 0.6945 \\
\hline \multirow[t]{2}{*}{ Phys } & Item25 & Causes pain & $1.42 \pm 0.84$ & $1.21 \pm 0.79$ & 0.21 & 0.3597 \\
\hline & Item26 & Physically limits & $1.37 \pm 1.12$ & $1.21 \pm 0.85$ & 0.16 & 0.6348 \\
\hline \multirow[t]{2}{*}{ No Factor } & Item53 & Irritable & $2.32 \pm 1.11$ & $2.05 \pm 1.22$ & 0.26 & 0.3098 \\
\hline & Item59 & Hostile & $1.68 \pm 1.16$ & $1.21 \pm 0.42$ & 0.47 & 0.0704 \\
\hline
\end{tabular}

${ }^{*}$ Excel (Microsoft, USA) item analysis; ${ }^{\dagger}$ Paired $\mathrm{t}$ test. FSC Facial self-consciousness; FS Full scale; GSC General self-consciousness; NSC Negative self-concept; Phys Physical distress and dysfunction; SBSC Sexual and bodily self-consciousness; SSC Social self-consciousness 


\begin{tabular}{|c|c|c|}
\hline \multicolumn{2}{|c|}{ DAS-59 item Label } & \multirow{2}{*}{$\begin{array}{c}P^{*} \\
0.0135\end{array}$} \\
\hline 1 & Self-consciousness of 'feature' & \\
\hline 10 & Avoiding photography & 0.0017 \\
\hline 27 & Feel unattractive & 0.0020 \\
\hline 28 & Feel unlovable & 0.0462 \\
\hline 34 & Distress when others make remarks & 0.0376 \\
\hline 42 & Distress when meeting strangers & 0.0491 \\
\hline 58 & How hurt do you feel? & 0.0045 \\
\hline 50 & $\begin{array}{l}\text { Distress when not being able to go to } \\
\text { pubs/restaurants }\end{array}$ & 0.0484 \\
\hline 49 & Distress from being unable to look in mirror & 0.0439 \\
\hline 52 & How confident do you feel? & 0.0119 \\
\hline 54 & How secure do you feel? & 0.0007 \\
\hline
\end{tabular}

${ }^{*}$ Paired t test

the item level. Differences in mean scores were significant $(\mathrm{P}<0.05$ based on paired $t$ test) for 11 items only (Table 4).

\section{DISCUSSION}

Assessing the outcomes of facial plastic surgery requires PRO instruments that ask specifically about appearance with a level of detail that makes it possible to measure clinically important change following treatment. Objective measures by a physician may not reflect patient perception of surgical success. Incorporating the patient perspective is an increasingly accepted notion in an era in which the focus of health care evaluation has moved from traditional clinical outcomes to the measurement of function and well-being (20).

The limitation of PRO assessment will always be the assessment tool or questionnaire with which we measure these outcomes. The paucity of reliable and valid questionnaires that are procedure- or condition-specific means that we may not capture all facets of a given procedure's outcome. They may not be sufficiently sensitive to measure the success of the intervention, or change specific to the condition of interest (7). In plastic and reconstructive surgery, it is important to have condition-specific measures given that generic measures often miss the issues that matter the most to patients. Appearance, for example, is often overlooked in generic PRO instruments (eg, Shortform 36, EQ-5D, Pediatric Quality of Life Inventory) but is a crucial outcome in plastic surgery.

We used the DAS-59 in the present study to quantify the effect of secondary rhinoplasty on CLP patients' appearance-based QoL because there is currently no cleft-specific tool available $(8,9)$. We found that compared with normative data, cleft patients in our study generally had higher DAS scores than the general population, suggesting greater concern with appearance generally in this group. There was reduction in DAS-59 scores after secondary rhinoplasty, indicating the patients were less self-conscious about their appearance, although still not sufficient to reduce scores to that of the general population.

Differences in FS were significant $(\mathrm{P}=0.002)$, as were GSC and NSC scores postrhinoplasty, indicating a beneficial effect of surgery.

There was a lack of significance in postoperative score change for the subscale pertaining to pain and physical limitations, which may be expected in our study group in which pain and physical limitation relating to their 'feature' may not be of significant concern to the patients.

The lack of significant change in the FSC subscale highlights an important limitation of using generic measures. In part, this may be due to the fact that this subscale, which on the surface sounds like an important concept, includes content that is not targeted to a rhinoplasty sample. Specifically, these four items were developed to measure concerns of pinnaplasty patients (ie, patients are asked if they "avoid getting their hair wet" and how distressed they are by "being unable to change their hairstyle, unable to answer the front door at home, and not able to go out in windy weather").

Careful inspection of the content of the DAS illustrates that the DAS is a validated measure of appearance-based QoL but is not specific to the CLP population. Such generic measures, despite their versatility in comparison across 'disease groups' or with population norms have important limitations when being used to measure detect change within a condition-specific group.

Item-by-item analysis showed a significant reduction in score in only 11 of 59 items (Table 4). These specific items would intuitively be of importance to a patient with a facial difference having surgery - feeling self-conscious of their feature, avoiding having their face photographed or viewed in a mirror, feeling unattractive, lacking confidence and feelings of security as well as concern with being in public spaces such as pubs or restaurants. Similarly, it may be expected that items relating to '... being able to go out in windy weather' or how 'feminine/masculine you feel' would not show a difference after facial surgery. It may be that in the present study, relatively few items drove overall differences in scores on the measure. As such, the scale may not accurately detect change across the range of concepts specific to the cleft population, although this analysis is subject to type 1 error due to the small sample size.

The need for such a measure that is properly developed, psychometrically robust and specific to the condition in question is apparent. Such a measure would allow meaningful evaluation of outcomes after surgery and more accurately measure change in health-related QoL. Development of a new internationally applicable PRO instrument for patients with CLP (ie, the CLEFT-Q) is currently in progress by an international team and aims to achieve this by comprehensively assessing concepts (appearance, speech and psychosocial function) that are important to this group (21).

\section{CONCLUSION}

CLP is the most common congenital facial difference, occurring in approximately one in 1000 live births (22). The demands it places on health care systems worldwide calls for a clinically meaningful, condition-specific measure for more accurate assessment of outcomes after surgical intervention. The present study demonstrates a beneficial effect of secondary rhinoplasty on appearance-based QoL; however, a condition-specific measure would more accurately quantify this benefit.

DISCLOSURES: The authors have no financial disclosures or conflicts of interest to declare.

\section{REFERENCES}

1. Guyuron B. MOC-PS(SM) CME Article: Late cleft lip nasal deformity. Plast Reconstr Surg 2008;121(Suppl):1-11.

2. Richman LC. Self-reported social, speech, and facial concerns and personality adjustment of adolescents with cleft lip and palate. Cleft Palate Craniofac J 1983;20:108-12.

3. Richman LC, Eliason M. Psychological characteristics of children with cleft lip and palate: Intellectual, achievement, behavioral and personality variables. Cleft Palate Craniofac J 1982;19:249-57.

4. Fitzpatrick R, Jenkinson C, Klassen A, Goodacre T. Methods of assessing health-related quality of life and outcome for plastic surgery. Br J Plast Surg 1999;52:251-5.

5. Cano SJ, Browne JP, Lamping DL. Patient-based measures of outcome in plastic surgery: Current approaches and future directions. Br J Plast Surg 2004;57:1-11.

6. Food and Drug Administration. Patient reported outcome measures. Use in medical product development to support labeling claims. 2006. $<$ www.fda.gov/cber/gdlns/prolbl.pdf> (Accessed December 3, 2015).

7. Cano SJ, Klassen A, Pusic AL. The science behind quality-of-life measurement: A primer for plastic surgeons. Plast Reconstr Surg 2009;123:98e-106e.

8. Eckstein DA, Wu RL, Akinbiyi T, Silver L, Taub PJ. Measuring quality of life in cleft lip and palate patients: Currently available 
patient-reported outcomes measures. Plast Reconstr Surg 2011;128:518e-526e.

9. Klassen AF, Tsangaris E, Forrest CR, et al. Quality of life of children treated for cleft lip and/or palate: A systematic review. Br J Plast Surg 2013;65:547-57.

10. Collett BR, Cloonan YK, Speltz ML, Anderka M, Werler MM. Psychosocial functioning in children with and without orofacial clefts and their parents. Cleft Palate Craniofac J 2012;49:397-405.

11. Warschausky S, Kay JB, Buchman S, Halberg A, Berger M. Healthrelated quality of life in children with craniofacial anomalies. Plast Reconstr Surg 2002;110:409-16.

12. Carr T, Harris D, James C. The Derriford Appearance Scale (DAS59): A new scale to measure individual responses to living with problems of appearance. Br J Health Psych 2010;5:201-15.

13. Harris DL, Carr AT. The Derriford Appearance Scale (DAS59): A new psychometric scale for the evaluation of patients with disfigurements and aesthetic problems of appearance. Br J Plast Surg 2001;54:216-22.

14. Ching S, Thoma A, McCabe RE, Antony MM. Measuring outcomes in aesthetic surgery: A comprehensive review of the literature. Plast Reconstr Surg 2003;111:469-80.

15. Carr T, Moss T, Harris D. The DAS24: A short form of the Derriford Appearance Scale DAS59 to measure individual responses to living with problems of appearance. Br J Health Psych 2010;10:285-98.
16. Marcusson A, List T, Paulin G. Reliability of a multidimensional questionnaire for adults with treated complete cleft lip and palate. Scand J Plast Reconstr Hand Surg 2001;35:271-8.

17. Cheung LK, Loh JSP, Ho SMY. Psychological profile of Chinese with cleft lip and palate deformities. Cleft Palate Craniofac J 2007;44:79-86.

18. Sinko K, Jagsch R, Prechtl V, Watzinger F, Hollmann K, Baumann A. Evaluation of esthetic, functional, and quality-of-life outcome in adult cleft lip and palate patients. Cleft Palate Craniofac J 2005;42:355-61.

19. Sarwer DB, Bartlett SP, Whitaker LA, Paige KT, Pertschuk MJ, Wadden TA. Adult psychological functioning of individuals born with craniofacial anomalies. Plast Reconstr Surg 1999;103:412-8.

20. Stewart AL, Ware JE, eds. Measuring Functioning and Well-Being: The Medical Outcomes Study Approach. Durham and London: Duke University Press, 1992.

21. Wong KW, Forrest CR, Goodacre TE, Klassen AF. Measuring outcomes in craniofacial and pediatric plastic surgery. Clin Plast Surg. 2013;40:305-12.

22. Dixon MJ, Marazita ML, Beaty TH, Murray JC. Cleft lip and palate: Understanding genetic and environmental influences. Nat Rev Genet 2011;12:167-78. 